\title{
Detection of Norwalk Virus in Stool Specimens by Reverse Transcriptase-Polymerase Chain Reaction and Nonradioactive Oligoprobes
}

\author{
R. DE LEON, ${ }^{1 \dagger}$ S. M. MATSUI, ${ }^{2}$ R. S. BARIC ${ }^{3}$ J. E. HERRMANN, ${ }^{4}$ N. R. BLACKLOW, ${ }^{4}$ \\ H. B. GREENBERG, ${ }^{2}$ AND M. D. SOBSEY ${ }^{1 *}$ \\ Department of Environmental Sciences and Engineering ${ }^{1}$ and Department of Epidemiology, Program in Infectious \\ Diseases, ${ }^{3}$ School of Public Health, University of North Carolina, Chapel Hill, North Carolina 27599; \\ Departments of Medicine (Gastroenterology) and Microbiology and Immunology, Stanford \\ University, Stanford, California 94305'; and Division of Infectious Diseases and \\ Immunology, University of Massachusetts Medical School, \\ Worcester, Massachusetts $01655^{4}$
}

Received 24 January 1992/Accepted 28 August 1992

\begin{abstract}
A reverse transcriptase (RT)-polymerase chain reaction (PCR)-oligoprobe (OP), or RT-PCR-OP, method was developed for the detection of the Norwalk virus, which causes acute, epidemic gastroenteritis, in stool specimens. The Norwalk virus genome regions encoding the following two proteins were amplified by RT-PCR: the RNA polymerase (260-bp product) and a putative immunogenic protein (224-bp product). The resulting DNA fragments (amplicons) were hybridized to a digoxigenin-labeled internal OP specific to each amplicon. The detection limit of Norwalk virus, as determined by the endpoint of RT-PCR amplification for serially diluted, positive stool specimens, was similar to the actual virion titer as estimated by electron microscopy and at least 100-fold greater than the titer determined by radioimmunoassay (RIA). The RT-PCR-OP assay was specific for Norwalk virus and negative for other enteric viruses, including human and animal caliciviruses, hepatitis $\mathbf{E}$ virus, Snow Mountain agent, astroviruses, 16 human enteroviruses, and 5 human rotaviruses. Components of fecal specimens that interfere with RT-PCR were removed successfully by Sephadex G-200 gel chromatography. Of 20 stool specimens from human volunteers that were positive for Norwalk virus by RIA, a specific RT-PCR-OP result was obtained in $95 \%$ (19 of 20$)$ of the samples by using the immunogenic protein primers and $75 \%$ (15 of 20) by using the polymerase primers. Twenty-six stool specimens from asymptomatic children and adults were negative by the Norwalk virus RT-PCR-OP. RT-PCR-OP detected Norwalk virus in the 4 of 21 coded fecal specimens that were also positive by enzyme immunoassay. Two samples that were positive by RIA or enzyme immunoassay were negative by RT-PCR, perhaps because viral RNA was not present or RT-PCR inhibitors were not adequately removed.
\end{abstract}

Norwalk virus is a major cause of gastroenteritis in older children and adults $(1,14)$ and is associated with epidemic disease in families, schools, other institutional settings, and communitywide outbreaks caused by contaminated water and food $(2,15)$. It is the prototype member of a poorly defined group of small, round gastrointestinal viruses that cause epidemic diarrhea $(7,9,14)$. Approximately $42 \%$ of outbreaks of acute nonbacterial gastroenteritis investigated by the Centers for Disease Control during 1976 to 1981 were caused by Norwalk virus and Norwalk virus-like viruses (15). The major clinical features of Norwalk gastroenteritis are nausea, vomiting, diarrhea, abdominal cramps, and headache lasting between 12 and $60 \mathrm{~h}(14,15)$. Antibodies to Norwalk virus have been detected in the populations of many industrialized and developing countries, indicating a worldwide distribution (1). Previous studies on Norwalk virus proteins and more recent studies on the cloning and partial sequencing of its nucleic acid have established that Norwalk virus is most likely a calicivirus $(10,13,17)$.

The diagnosis of Norwalk virus gastroenteritis is currently based on clinical observations combined with the detection

\footnotetext{
* Corresponding author.

+ Present address: Department of Environmental Analysis and Design, School of Social Ecology, University of California-Irvine, Irvine, CA 92717.
}

of viral antigens or patient seroconversion. Identification of Norwalk virus by direct electron microscopy is often not possible because its surface morphology is not sufficiently distinctive and the virus is shed in feces in relatively low numbers $\left(10^{4}\right.$ to $10^{6} / \mathrm{g}$ of feces) (14). Immune electron microscopy (IEM) can be used to observe viral particles that have been specifically aggregated with postinfection serum, but this method is tedious and insensitive. Currently, radioimmunoassay (RIA) and enzyme immunoassay (EIA) are the methods of choice for identification of Norwalk virus infections because they are more efficient than and are at least as sensitive as IEM in detecting viral antigens or antibodies (11). However, these diagnostic tests currently have limited application in clinical laboratories because reagent quality and Norwalk virus-specific antigens and antibodies are not widely available and because both acute- and convalescent-phase sera are required to diagnose suspected cases serologically. A specific and generally accessible diagnostic test for Norwalk virus, one that does not cross-react with other small, round gastrointestinal viruses or other enteric viruses, is needed.

The cloning of a large portion of the Norwalk virus genome and the availability of nucleotide sequence data for genomic regions encoding the RNA polymerase (Pol) (13) and an immunogenic protein (IP) (17) have made possible the detection of Norwalk virus RNA by cDNA probe hybridization (17). Furthermore, it should now be possible to develop 
highly sensitive methods to detect Norwalk virus in clinical specimens by reverse transcriptase (RT)-polymerase chain reaction (PCR).

Detection of enteric viruses in fecal specimens by RT-PCR has been described recently for a number of viruses including group A rotaviruses $(8,23)$, group B rotaviruses (6), enteroviruses (21), and hepatitis $A$ virus $(12,20)$. In most of these studies, viral RNA was isolated by conventional phenol-chloroform extraction and ethanol precipitation, and in some studies $(6,23)$, the viral RNA was further processed for removal of RT-PCR inhibitors by adsorption to and elution from CF-11 cellulose. These sample preparation methods are cumbersome and time-consuming and are not readily applicable in clinical laboratories. Likewise, the removal of RT-PCR inhibitors by antigen-capture PCR (12) is not feasible at present, because the required monoclonal or monospecific antibodies for Norwalk virus are not yet available. It is clear that a rapid and simple method for fecal specimen preparation is needed for routine detection of Norwalk virus by RT-PCR. In this report, we describe an efficient and widely applicable technique that can be used to detect Norwalk virus in fecal specimens. Our approach consisted of partial purification of virus from fecal material by spin-column chromatography (3); this was followed by RT-PCR amplification and confirmation of RT-PCR product specificity by use of a nonradioactive oligoprobe (OP).

\section{MATERIALS AND METHODS}

Viruses and stool specimens. Norwalk virus was obtained as stool samples from human volunteers experimentally infected with the 8FIIa Norwalk inoculum (a gift of G. W. Gary, Centers for Disease Control, Atlanta, Ga.). Additional stool specimens containing the Norwalk virus-like or calicivirus-like viruses designated Hawaii agent, Parramatta agent, Taunton agent, Snow Mountain agent, UK4, 20862, $1120, R, J$, and S were obtained from our collections (J.E.H., N.R.B., and M.D.S.). Hepatitis E virus in acute-phase stool specimens from an experimentally infected cynomolgus monkey was obtained from J. Ticehurst (Walter Reed Army Institute for Research, Washington, D.C.). Coxsackievirus type Al was obtained as homogenized mouse tissue from the American Type Culture Collection (Rockville, Md.). The following cell culture-propagated viruses were obtained from the indicated sources: feline caliciviruses 2280 and LLK, F. Schaffer (Naval Biomedical Research Laboratory, Oakland, Calif.); human rotavirus strain Wa and isolate 62 (type 1), isolate 126 (type 2), strain P (type 3), and isolate 204 (type 4), R. L. Ward (The Christ Hospital Institute of Medical Research, Cincinnati, Ohio); human astrovirus types 1, 2, and 4, J. E. Herrmann; and hepatitis A virus (strain HM175), polioviruses 1 and 3 , coxsackieviruses types A5, A9, A12, $A 17, B 3$, and B4, and echoviruses $1,2,4,5,7$, and 12 , the collection of M. D. Sobsey.

Sample processing for PCR. Ten or $20 \%$ stool suspensions in phosphate-buffered saline were clarified by centrifugation $(1,000 \times g)$ for $5 \mathrm{~min}$ and were filter sterilized through $0.45-\mu \mathrm{m}$-pore-size membrane filters (Low Protein Binding Sterile Acrodisc; Gelman Sciences, Ann Arbor, Mich.) that had been pretreated with $0.1 \%$ Tween 80 and washed with sterile distilled water. The Norwalk virus-positive stool suspensions used for the initial studies were fluorocarbon (1,1,2-trichloro-1,2,2,-trifluoroethane; Fisher Scientific, Fair Lawn, N.J.) extracted prior to clarification and filtration. When a stool sample was available in only a small quantity $(<100 \mu \mathrm{l})$, it was clarified by centrifugation at $14,000 \times g$ for
TABLE 1. Norwalk virus primers and oligoprobes

\begin{tabular}{|c|c|c|c|c|}
\hline $\begin{array}{l}\text { Oligonucleotide } \\
\text { primer or } \\
\text { probe }\end{array}$ & Sequence & $\begin{array}{c}T_{m} \\
\left({ }^{\circ} \mathrm{C}\right)^{a}\end{array}$ & $\begin{array}{c}T_{d} \\
\left({ }^{\circ} \mathrm{C}\right)^{b}\end{array}$ & $\begin{array}{l}\text { Fragment } \\
\text { length } \\
\text { (bp) }\end{array}$ \\
\hline \multicolumn{5}{|l|}{ Pol gene } \\
\hline NV-5'Pol & CAAATTATGACAGAATCCTTC & 43.3 & & \\
\hline NV-3'Pol & GAGAAATATGACATGGATTGC & 46.3 & & 260 \\
\hline NV-Io.Pol & ATGTCATCAGGGTCAAAGAGG & & 63.0 & \\
\hline \multicolumn{5}{|l|}{ IP $^{c}$} \\
\hline NV-5'IP & CACCACCATAAACAGGCTG & 48.5 & & \\
\hline NV-3'IP & AGCCTGATAGAGCATTCTTT & 45.2 & & 224 \\
\hline NV-Io.IP & TGCGTTCACGAGGATGG & & 62.7 & \\
\hline
\end{tabular}

${ }^{a}$ The $T_{m}$ of primers was calculated at $50 \mathrm{mM}$ salt and solution hybridization conditions.

${ }^{b}$ The $T_{d}$ of oligoprobes was calculated at $1,000 \mathrm{mM}$ salt and filter hybridization conditions $\left(-7.6^{\circ} \mathrm{C}\right)$.

c The primers for this region have been published previously (17). The internal oligomer was selected in this study.

3 to $5 \mathrm{~min}$, and the supernatant was applied directly to the spin columns. Viruses in the clarified stool sample extracts were purified by exclusion chromatography by using Sephadex G-200 spin columns (bead size, 40 to $120 \mu \mathrm{m}$ [diameter]; Pharmacia, Piscataway, N.J.). Spin columns were prepared as described by Maniatis et al. (16), except that silane-treated glass wool (Supelco, Bellafonte, Pa.) was used as the column support. In order to prevent the Sephadex G-200 gel from crushing under centrifugal force, the columns were prepared in 3-ml syringes and spun at $400 \times \mathrm{g}$ and room temperature for $4 \mathrm{~min}$. Approximately 75 to $85 \mu \mathrm{l}$ of sample was passed through a $1-\mathrm{ml}$ column (1:12 sample-to-resin ratio) that had been equilibrated with $0.1 \times$ Taq buffer II (Perkin Elmer-Cetus, Emeryville, Calif.). Viruses were recovered in the excluded volume, which averaged 70 to $80 \mu \mathrm{l}$ per column, and $10 \mu \mathrm{l}$ was used for each RT-PCR. Viruses grown in cell cultures were diluted 10- to 100-fold in $0.1 \times$ Taq buffer II (Perkin Elmer-Cetus), and $10 \mu l$ containing approximately $10^{3}$ to $10^{4}$ tissue culture infectious units was used directly for RT-PCR.

Primers and probes. The oligonucleotide primer and probe sequences used in this study are summarized in Table 1 . The primers NV-5' Pol and NV-3'Pol and the internal oligonucleotide probe NV-Io.Pol were selected from published nucleotide sequences in the Norwalk virus Pol gene (13). The primers NV-5' IP and NV-3'IP, from a region encoding an IP, were those described previously (17), and an internal oligonucleotide, NV-Io.IP, was selected from the known sequence data. The Norwalk virus-specific primers and probes were selected by using computer-aided nucleic acid sequence alignments $(5)$ and protein alignments $(13,18)$ for caliciviruses and picornaviruses. The internal oligomer probes NV-Io.Pol and NV-Io.IP were synthesized in the plus-sense orientation so that they hybridized only with cDNA or PCR products and not with viral genomic plusstrand RNA. The DNA oligomers were synthesized as single-stranded DNA by using an automated synthesizer (model 392; Applied Biosystems Inc., Foster City, Calif.). The melting temperatures $\left(T_{m} s\right)$ of the primers and the denaturation temperatures $\left(T_{d} \mathrm{~s}\right)$ of the oligoprobes were calculated with the aid of the OLIGO program (22).

Reverse transcription and enzymatic amplification (RTPCR). The RNA PCR kit from Perkin Elmer-Cetus was used throughout the study. The manufacturer's instructions were followed, with the exception that the reaction volume for 
reverse transcription was increased from 20 to $30 \mu l$ to accommodate a $10-\mu l$ virus sample. Random primers were used during reverse transcription of viral RNA, and primer pairs for either the Pol gene (NV-Pol) or the IP (NV-IP) were used for PCR amplification. The reaction mixture was prepared in a single tube and was dispensed into individual 0.6-ml polypropylene reaction tubes for all samples within a single trial. Each tube was overlaid with $100 \mu l$ of mineral oil (Sigma Chemical Co., St. Louis, Mo.) prior to adding $10 \mu \mathrm{l}$ of processed stool sample. Viral RNA was released by heating the prepared reaction mixtures at $99^{\circ} \mathrm{C}$ for $5 \mathrm{~min}$ in a thermal cycler (Perkin Elmer-Cetus, Norwalk, Conn.), and the reaction mixtures were then chilled on ice for $1 \mathrm{~min}$. RT $(2.5 \mathrm{U})$ and RNase inhibitor $(1 \mathrm{U})$ were subsequently added beneath the oil as described in the kit. Samples were placed in the thermal cycler for $10 \mathrm{~min}$ at $25^{\circ} \mathrm{C}$; this was followed by a 1-h incubation at $42^{\circ} \mathrm{C}$. After cDNA synthesis, sample tubes were heated to $99^{\circ} \mathrm{C}$ for $5 \mathrm{~min}$ to completely denature the RT. After brief centrifugation, either NV.Pol or NV.IP primer pairs and $5 \mathrm{U}$ of Taq polymerase were added to each tube. Reaction tubes were placed in the thermal cycler when the block temperature was $>85^{\circ} \mathrm{C}$. Samples were amplified in the thermal cycler for 40 cycles by using the cycle sequence of $95^{\circ} \mathrm{C}$ for $1.5 \mathrm{~min}, 50^{\circ} \mathrm{C}$ (IP region primers) or $55^{\circ} \mathrm{C}$ (Pol region primers) for $1.5 \mathrm{~min}$, and $72^{\circ} \mathrm{C}$ for $1.5 \mathrm{~min}$. After amplification, 10 to $15 \%$ of the reaction volumes were electrophoresed in $2 \%$ agarose gels, stained with ethidium bromide, and visualized by UV light.

OP hybridization. PCR products in agarose gels were transferred by the method of Southern onto nylon membranes (DuPont, Boston, Mass.). The DNA was bound to the nylon membranes by cross-linking with shortwave UV light (Ultraviolet Products Inc., San Gabriel, Calif.) for 3 to $5 \mathrm{~min}$ at a distance of $15 \mathrm{~cm}$.

OPs were 3 '-end-labeled with digoxigenin-dUTP by using terminal transferase and were purified by ethanol precipitation, according to the instructions in the Genius nonradioactive end-labeling kit (Boehringer Mannheim Biochemicals, Indianapolis, Ind.). The $T_{d}$ of each oligomer was calculated in $5 \times \mathrm{SSC}(1 \times \mathrm{SSC}$ is $0.15 \mathrm{M} \mathrm{NaCl}$ plus $0.015 \mathrm{M}$ sodium citrate; $56.7^{\circ} \mathrm{C}$ for NV-Io.Pol and $56.4^{\circ} \mathrm{C}$ for NV-Io.IP). OP hybridization and immunological detection of positive samples were performed by following the specifications in the kit (Boehringer Mannhein Biochemicals). Briefty, membranes were prehybridized for $4 \mathrm{~h}$ and were hybridized overnight at $T_{d}-5^{\circ} \mathrm{C}$ in the hybridization buffer recommended in the kit (5x SSC, $0.1 \%$ [wt/vol] $N$-lauroylsarcosine, $0.02 \%$ [wt/vol] sodium dodecyl sulfate, and $1 \%$ [wt/vol] proprietary blocking reagent of Boehringer Mannheim Biochemicals). The probe was present at a concentration of 5 to $10 \mathrm{ng}$ per ml of hybridization solution. The blots were washed five times in $6 \times \mathrm{SSC}-0.05 \% \mathrm{PP}_{\mathrm{i}}$ at $T_{d}-5^{\circ} \mathrm{C}$ of the oligo-PCR product hybrid $\left(58^{\circ} \mathrm{C}\right.$; calculated in $\left.6 \times \mathrm{SSC}\right)$. Both OPs were washed at $58^{\circ} \mathrm{C}$ because their $T_{d} \mathrm{~s}-5^{\circ} \mathrm{C}$ differed only by $0.3^{\circ} \mathrm{C}$. Immunological detection of PCR product-OP hybrids was performed by using an anti-digoxigenin alkaline phosphatase antibody conjugate and enzyme catalyzed colorimetric reaction with 5-bromo-4-chloro-3-indolyl phosphate and nitroblue tetrazolium salt as substrates.

\section{RESULTS}

RT-PCR amplification of Norwalk virus. The stool samples used in the initial studies (8FIIa, G-52, G-53, L-152, and L-153) were obtained from human volunteer studies and were previously shown to contain Norwalk virus by IEM or

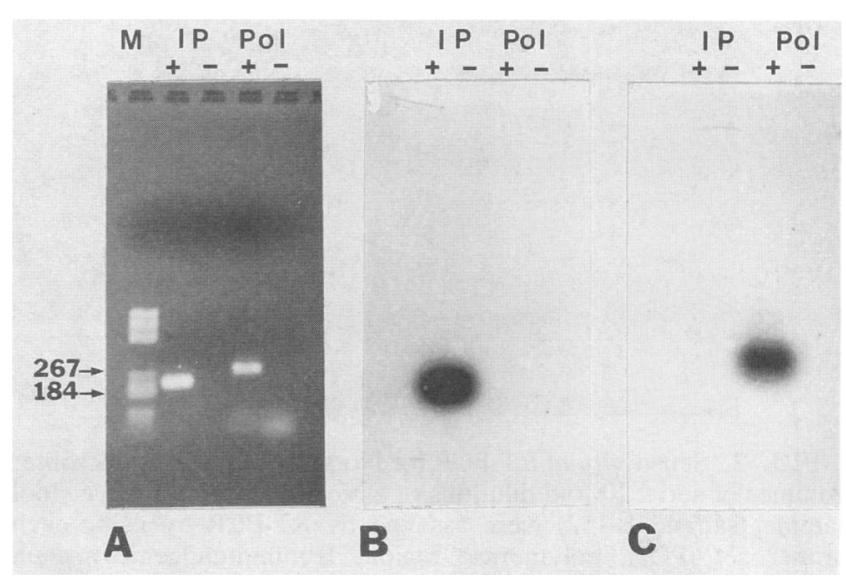

FIG. 1. RT-PCR and oligoprobing of Norwalk virus. Nucleic acid of Norwalk virus purified from a stool specimen (sample L-152) by Sephadex G-200 chromatography was amplified from two different genomic regions, an IP region and the Pol region, in separate reactions (A). Southern transfers were hybridized with OPs to either the IP region (B) or the Pol region (C). M, DNA markers (DNA marker V; Boehringer Mannheim Biochemicals); IP+, Norwalk virus amplified by primers from an immunogenic protein region with a resulting DNA fragment of 224 bp; IP - , reaction cocktail containing IP primers but no Norwalk virus; Pol + , Norwalk virus amplified by primers from the Pol region with a resulting DNA fragment of 260 bp; Pol-, reaction cocktail containing Pol primers but no Norwalk virus.

solid-phase immunoassay (RIA or EIA) or both methods. As shown in Fig. 1A, Norwalk virus sequences from the IP and Pol regions were effectively amplified by the primer pairs NV-IP and NV-Pol and resulted in the expected amplicons of 224 and $260 \mathrm{bp}$, respectively. No amplicons were detected in Norwalk-negative reaction mixtures (Fig. 1A, lanes marked with a minus sign). The digoxigenin-labeled probes NV-Io.IP and NV-Io.Pol, which were internal to their respective amplicons, were used to verify the authenticities of Norwalk virus-derived PCR DNA fragments. The IP region OP was specific to the amplified 224-bp DNA fragment (Fig. $1 B)$, and the Pol region OP was specific to the 260-bp fragment (Fig. 1C).

Sensitivity of RT-PCR. The sensitivity of the RT-PCR method was determined on a Norwalk virus-containing stool filtrate, the titer of which was previously determined by IEM and RIA. RT-PCR detection with the NV-IP and NV-Pol primer pairs was applied to serial 10 -fold dilutions of a Norwalk virus-positive stool sample (sample L-152) estimated to contain about $10^{6}$ virions per ml by IEM (6a) and to have an RIA dilution endpoint titer of about $1: 2,048\left(10^{3.3}\right)$. As shown in Fig. 2, a RT-PCR endpoint titer of $10^{6} / \mathrm{ml}$ was obtained by using each primer set. The safety-tested 8FIIa stool specimen inoculum used in human volunteer studies had a similar endpoint titer by RT-PCR (data not shown). This specimen was previously shown to contain approximately $10^{6}$ particles per ml by IEM (17), to have an RIA dilution endpoint titer of about $10^{3.5} / \mathrm{ml}(11)$, and to have a human infectivity titer of at least $10^{4}$ infectious doses per ml (14). These results indicate that RT-PCR is at least 100 -fold more sensitive than RIA and considerably more sensitive than IEM for Norwalk virus detection in stools. By IEM, it generally is not possible to detect virions at titers of less than about $10^{6} / \mathrm{ml}$ (the practical detection limit), but by RT-PCR, 


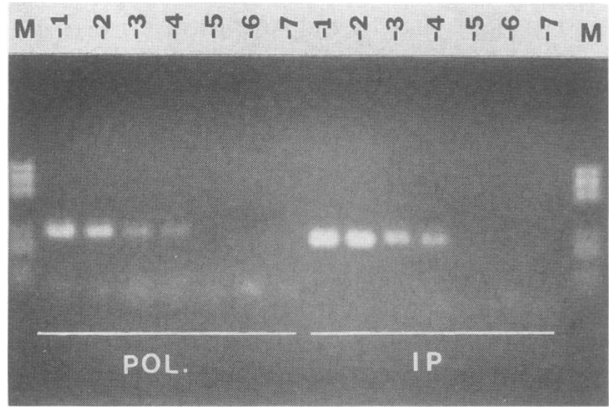

FIG. 2. Sensitivity of RT-PCR for Norwalk virus. Ten-microliter volumes of serial 10 -fold dilutions of a Norwalk virus-positive stool sample (sample L-152) were assayed by RT-PCR by using each primer set (POL, polymerase region; IP, immunogenic protein region) in separate reactions. Both RT-PCR reactions gave a distinct endpoint of positivity at a $10^{-4}$ dilution, corresponding to $10^{6} / \mathrm{ml} . \mathrm{M}$, DNA markers (marker V; Boehringer Mannheim Biochemicals); lanes -1 through $-7,10$ - $\mu$ l samples of serial 10 -fold dilutions of Norwalk virus stool specimen containing an estimated $10^{6}$ virions per ml.

it was possible to dilute such specimens 10,000 -fold and still detect genomic nucleic acid in a $10-\mu$ l volume.

The endpoints of Norwalk virus RT-PCR titrations were sharp after 40 cycles of amplification, which is consistent with RT-PCR endpoint titration results reported previously for other enteric viruses (4). Norwalk virus RT-PCR titrations had the same endpoints by UV light visualization of ethidium bromide-stained gels and by digoxigenin-labeled OP hybridization under the conditions tested in this study.

Specificity of RT-PCR-OP detection. It was considered essential that the detection method for Norwalk virus not react with other enteric viruses commonly shed in feces. Computer-aided analysis of genomic RNA sequences strongly suggested that the primers selected for Norwalk virus were specific. Nonetheless, extensive empirical testing was performed to verify specificity, because sequence information on some enteric viruses possibly related to Norwalk virus is not available. The specificities of both sets of primers and OPs were determined by performing RT-PCR-OPs on other calicivirus-like and Norwalk virus-like small, round gastrointestinal viruses, astroviruses, enteroviruses, and rotaviruses. By using both Norwalk virus primer-OP sets, RT-PCR-OP results were negative when tested with human caliciviruses (specimens UK4, 20682, 1120, R, J, and S), two feline caliciviruses, a canine calicivirus, Snow Mountain agent, and hepatitis $\mathrm{E}$ virus. Reactions were also negative for human astrovirus types 1,2 , and 4; Parramatta agent; Hawaii agent; Taunton agent; 15 enteroviruses (poliovirus types 1 and 3; coxsackievirus types A1, A5, A9, A12, A17, B3, and B5; echovirus types $1,2,4,5,7$, and 12); hepatitis A virus; and group A rotavirus strain $W a$ and isolate 62 (type 1 ), isolate 126 (type 2), strain P (type 3), and isolate 204 (type 4). Twenty-six stool specimens from asymptomatic children and adults were negative by RT-PCR-OP. All of the enteroviruses and rotaviruses tested were positive by RT-PCR by using pan-enterovirus or pan-rotavirus primers (data not shown).

Detection of Norwalk virus in fecal specimens. We next used our RT-PCR-OP assay to study serial shedding of Norwalk virus by human volunteers. Detection of Norwalk virus in stool samples by RT-PCR-OP was compared with antigen detection by RIA and viral RNA detection by dot

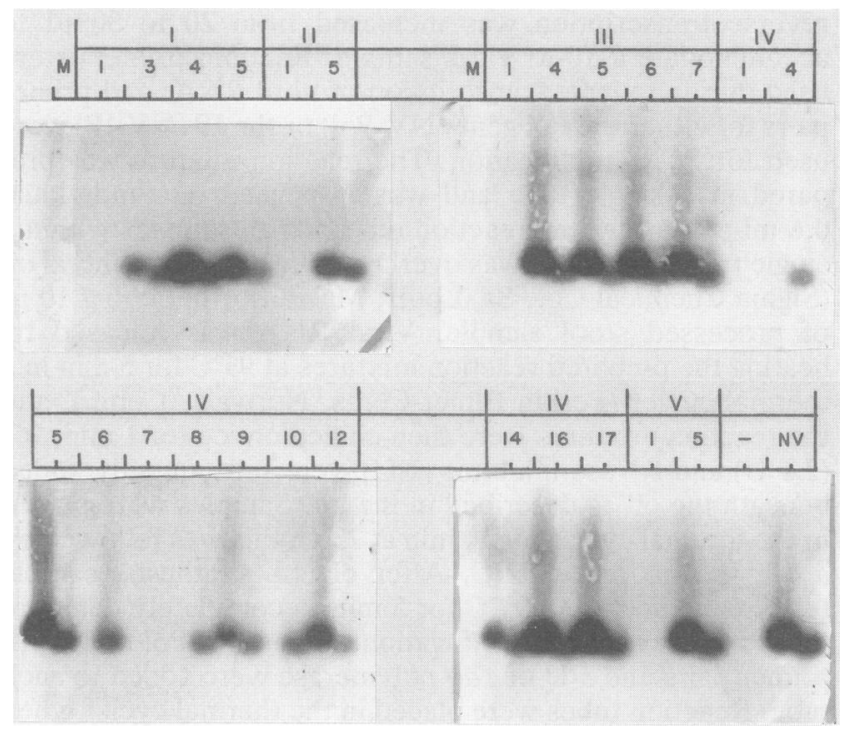

FIG. 3. Detection by RT-PCR-OP of Norwalk virus in serial stool specimens from experimentally infected human volunteers. Stool samples were purified by Sephadex G-200 gel chromatography, amplified by RT-PCR, transferred by the method of Southern, and hybridized with Pol and IP oligoprobes simultaneously. Roman numerals, volunteer number; arabic numerals, stool sample number (sample no. 1 is the preinfection stool sample). For each stool sample, the left lane is the Pol oligoprobe (upper bands) and the right lane is the IP oligoprobe (lower bands). M, DNA molecular weight markers; NV, Norwalk virus positive control.

blot hybridization with pre- and postinfection stool samples from five experimentally infected human volunteers. All of the 20 postinfection stool samples tested by RT-PCR-OP were previously found to be Norwalk antigen positive by RIA (positive/negative, >2) (17). All five preinfection stool samples (I-1, II-1, III-1, IV-1, and V-1) were negative by RT-PCR-OP when both primer-OP sets were used. By RT-PCR-OP, 95\% (19 of 20) of RIA-positive postinfection stool samples were positive when the IP primer-OP set (NV-IP and NV-Io.IP) was used and $70 \%$ were positive when the Pol primer-OP set (NV-Pol and NV-Io.Pol) was used (Fig. 3). All samples that were positive with the NV-Pol primers were also positive with the NV-IP primers. Only one RIA-positive sample (sample IV-7) was RT-PCR-OP negative with both primer sets. Because of the small amount of sample available, we were not able to determine whether RT-PCR was inhibited or viral RNA was degraded.

For stool samples from four of five infected volunteers (volunteers I, II, III, and V), there was complete agreement between the results of RT-PCR-OP when both primer-OP sets were used and there was antigen positivity by RIA. However, differences in sample positivity were obtained for postinfection stool samples from volunteer IV. Although all 11 postinfection stool samples were antigen positive by RIA, 10 were positive by RT-PCR-OP when the IP primer-OP set was used and only 6 were positive when the Pol primer-OP set was used.

The applicability of the RT-PCR-OP method to the detection of Norwalk virus in clinical isolates was determined by using a series of coded stool samples. Twenty-one coded stool specimens, including several Norwalk virus EIA-positive stool specimens as well as stool specimens containing caliciviruses, astroviruses, and an adenovirus, were tested 

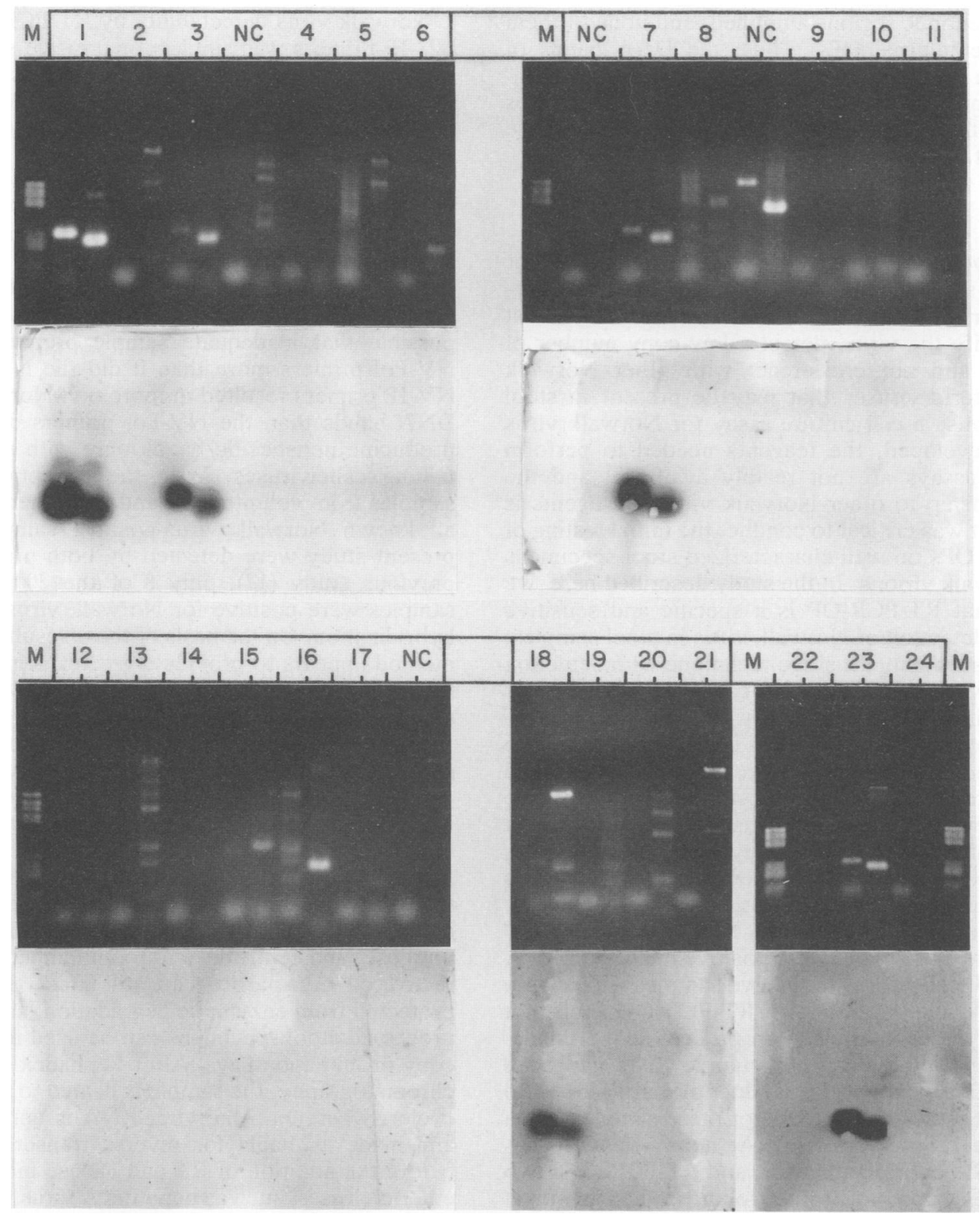

FIG. 4. Detection of Norwalk virus by RT-PCR-OP in stool specimens. For agarose gels, 21 coded stool specimens were purified by Sephadex G-200 spin-column chromatography, amplified by RT-PCR by using Norwalk virus NV-5'Pol and NV-3'Pol primers (left lane below each number) and NV-5'IP and NV-3'IP primers (right lane below each number) in separate reactions. For hybridization filters, Southern transfers of amplified reaction products were probed with digoxigenin-labeled oligomers (Pol, left lane; IP, right lane). Lanes: 1, Norwalk virus, volunteer sample I; 2, Parramatta agent; 3, Norwalk virus, volunteer sample II; 4, negative stool, child; 5, calicivirus J; 6, calicivirus 1120; 7, Norwalk virus, volunteer sample III; 8 , astrovirus type $1 ; 9$, negative stool sample, adult; 10 , Norwalk virus, volunteer stool sample collected on the day of infection; 11, Parramatta agent; 12, astrovirus type 4; 13, Norwalk virus volunteer, preinfection stool sample; 14, calicivirus S; 15, calicivirus R; 16, adenovirus; 17, Norwalk virus, volunteer sample IV preserved in sodium azide; 18, Norwalk virus, volunteer sample V; 19, Hawaii agent; 20, Taunton agent; 21, Norwalk virus volunteer, early postinfection stool sample (negative by EIA); 22, negative stool sample, child; 23, Norwalk virus positive control stool sample; 24, reagent control; NC, negative controls; M, DNA molecular weight markers (marker V; Boehringer Mannheim Biochemicals).

for Norwalk virus by RT-PCR-OP. Four samples were clearly Norwalk virus positive when both primer-OP sets were used (Fig. 4). These four samples were also EIA positive. An additional sample that was positive by EIA (sample 17) but negative by RT-PCR-OP was obtained in 1978 and had been preserved in sodium azide. All samples negative for Norwalk virus by EIA were also negative by RT-PCR-OP. Non-Norwalk virus-specific DNA bands were observed as RT-PCR products in ethidium bromide-stained, electrophoresed agarose gels of samples containing caliciviruses (Fig. 4). In most cases, these bands were clearly different in size from the 260- and 224-bp bands of the 
Norwalk virus genomic regions amplified, and none of them reacted with the internal OPs. Thus, the DNA bands of predicted size in Norwalk virus-positive specimens hybridized to their respective internal OPs, while all other viruses present in the samples tested were negative by the complete RT-PCR-OP test.

\section{DISCUSSION}

In order to develop a useful, PCR-based diagnostic test for Norwalk virus, several important factors must be considered. The primers and OPs selected for Norwalk virus must effectively amplify the virus, detect a low copy number of genomic RNA, and not cross-react with other Norwalk virus-like or enteric viruses that may be present in stool specimens. Because a cell culture assay for Norwalk virus has not been developed, the reagents needed to perform antibody-based assays are not readily available, and the genomic relationship to other Norwalk virus-like agents is not yet known, it was critical to conduct the initial testing of the primers and OPs on well-characterized stool specimens containing Norwalk virions. In the study described here, we demonstrated that RT-PCR-OP is a specific and sensitive method for the detection of Norwalk virus in stool samples.

RT-PCR-OP is a highly sensitive technique with detection limits at or below the dose levels that cause clinical illness or infection. The titration endpoints that we obtained by RTPCR-OP of Norwalk virus from stool specimens were more than 100-fold greater than the dilution endpoint titer detected by RIA and were equivalent to the estimated virus particle count obtained by IEM. In samples that contained virions at the practical limit of IEM detectability of about $10^{6}$ virions per ml, RT-PCR detection was achieved in $10-\mu$ l volumes when such specimens were diluted as much as 10,000-fold. Stool samples having Norwalk virus RIA or EIA positive/ negative values of 2 or greater were positive by RT-PCR-OP, with a few noted exceptions. In the two samples which were positive by RIA and negative by RT-PCR-OP, it is not known whether the sample clean-up procedure was inadequate in removing inhibitors, the genomic RNA had been degraded, or RIA positivity was due primarily to viral antigens and not intact virions. One of these samples had a positive/negative ratio of 5.6 by RIA; nonetheless, it was negative by cDNA hybridization (17) and RT-PCR. The two following samples from the same volunteer had positive/ negative ratios of 3.2 and 3.9 by RIA, were positive by cDNA hybridization (17), and were positive by RT-PCR.

Detection of Norwalk virus by the RT-PCR-OP method developed in the study described here was specific. Both sets of primer pairs gave the specific PCR product from Norwalk virus-positive stools but not from negative control stools or from a variety of enteric viruses tested. DNA bands of different sizes were occasionally observed after amplification of other caliciviruses. This reactivity may reflect either some degree of sequence conservation in the RNA Pol of Norwalk virus and these other viruses or nonspecific bands not associated with the Pol region of these viruses. However, no reactivity with the internal OPs was observed for any viruses tested by hybridization after RT-PCR amplification. Because the internal OPs hybridized only to their Norwalk virus-derived amplicons and not to other DNA bands, oligoprobing of PCR-amplified stool specimens is a reliable confirmatory step for identification of those stool samples containing Norwalk virus. Such confirmation seems to be necessary until other Norwalk virus-like viruses are sequenced and more specific primers can be selected.
Norwalk virus detectability by RT-PCR with NV-Pol and NV-IP primers was similar for positive stools from four of five volunteers and for coded clinical samples. However, visual observation of PCR products in electrophoresed agarose gels suggested that the NV-IP primers produced more PCR product than the NV-Pol primers did. The NV-Pol primers were annealed at a higher temperature $\left(\mathrm{ca} .10^{\circ} \mathrm{C}\right.$ above the $T_{m}$ ) than the NV-IP primers were $\left(\mathrm{ca} .5^{\circ} \mathrm{C}\right.$ above the $\left.T_{m}\right)$. This difference in stringency may have accounted for the greater yield of PCR product and better detection in a set of stool samples from one of the five volunteers (volunteer IV) when the NV-IP primers were used. It is also possible that inadequate sample preparation affected the NV-Pol primers more than it did the NV-IP primers. The NV-IP primers resulted in more non-Norwalk virus-specific DNA bands than the NV-Pol primers did, with the latter producing nonspecific bands only with stool samples containing caliciviruses. With the exception of some stool samples from volunteer IV and one other volunteer sample, all known Norwalk virus-positive samples tested in the present study were detected by both primer-OP sets. In a previous study (17), only 8 of the 20 postinfection stool samples were positive for Norwalk virus RNA by dot blot hybridization. On the basis of these results, the RT-PCR-OP method appears to provide a greater degree of detectability than does direct hybridization of Norwalk virus RNA in stool samples.

The processing of virus-containing stool samples by Sephadex G-200 spin-column chromatography is a rapid, practical, and effective approach for removal of factors that interfere with RT-PCR. Viruses are recovered efficiently in a buffer compatible with RT-PCR, and they are substantially free of small proteins, salts, and other nonspecific factors that might interfere with RT-PCR. The Sephadex G-200 spin columns can be easily prepared in quantity, stored at $4^{\circ} \mathrm{C}$ until use, and centrifuged at room temperature. Because the recovered virus particles are still intact, the genomic RNA is protected from enzymatic degradation, and additionally, the processed stool specimens can be used for electron microscopy or immunoassays. After Sephadex G-200 spin-column chromatography, the sample is heated to $99^{\circ} \mathrm{C}$ in the thermal cycler, whereupon the viral RNA is conveniently released and made available for reverse transcription immediately before the addition of RT and RNase inhibitors (12). Other enteric viruses, such as hepatitis A virus, enteroviruses, and rotaviruses, can also be processed effectively in this manner (4).

Although other methods are available for the preparation of stool samples for RT-PCR, they have drawbacks in comparison with the gel chromatography method used in the present study. Methods based on phenol-chloroform extraction, ethanol precipitation of viral RNA, and CF-11 cellulose chromatography are cumbersome, labor-intensive, timeconsuming, and potentially damaging to the integrity of the viral genome. Antibody capture of viral antigen on a solid phase has also been demonstrated to be effective in removing factors that interfere with RT-PCR from stool samples in the detection of hepatitis A virus (12). At present, however, this approach is not applicable to the detection of Norwalk virus, because the high-quality Norwalk virus-specific antibodies needed for antigen capture are not readily available.

The RT-PCR-OP technique described here is well-suited for the detection of pedigree Norwalk virus and, as sequence information becomes available, other Norwalk virus-like agents of acute gastrointestinal illness. The high degree of sensitivity of target nucleic acid amplification techniques, 
such as RT-PCR, is important for the detection of noncultivatable viruses because they may be shed in low numbers in feces and because stool specimens may not be collected during the period of peak virus shedding. The use of nonradioactive OPs provides a confirmatory test to the clinical laboratory without the risk of handling radioactive material. As issues such as false-positive results by PCR product carryover, false-negative results by factors that interfere with RT-PCR, primer and OP specificity, and automation continue to be addressed, PCR technology for the detection of low levels of fastidious viruses is likely to become ever more accessible to the clinical diagnostic laboratory (19).

\section{ACKNOWLEDGMENTS}

We thark Joseph DiCesare, Perkin Elmer-Cetus, for advice and assistance.

These studies were supported in part by grants (to J.E.H. and N.R.B.) from the Thrasher Research Fund and DAMD 17-86-C6196 from the U.S. Army Medical Research and Development Command.

\section{REFERENCES}

1. Blacklow, N. R., and H. B. Greenberg. 1991. Viral gastroenteritis. N. Engl. J. Med. 325:252-264.

2. Cukor, G., and N. R. Blacklow. 1984. Human viral gastroenteritis. Microbiol. Rev. 48:157-179.

3. De Leon, R. 1989. Use of gene probes and an amplification method for the detection of rotaviruses in water. Ph.D. thesis. University of Arizona, Tucson.

4. De Leon, R., C. Shieh, R. S. Baric, and M. D. Sobsey. 1990. Detection of enteroviruses and hepatitis A virus in environmental samples by gene probes and polymerase chain reaction, $p$. 833-853. In Proceedings of the 1990 Water Quality Technology Conference. American Water Works Association, Denver.

5. Deveraux, J., P. Haeberli, and O. Smithies. 1984. A comprehensive set of sequence analysis programs for the VAX. Nucleic Acids Res. 12:387-395.

6. Eiden, J. J., J. Wilde, F. Firoozmand, and R. Yolken. 1991. Detection of animal and human group $B$ rotaviruses in fecal specimens by polymerase chain reaction. J. Clin. Microbiol. 29:539-543.

6a.Gary, G. W., and C. Gravelle (Centers for Disease Control, Atlanta, Ga.). Personal communication.

7. Glass, R. I., S. S. Monroe, S. Stine, P. Madore, D. Lewis, D. Cubitt, G. Grohmann, and C. Ashley. 1989. Small round structured viruses: the Norwalk family of agents, p. 87-90. In M. J. G. Farthing (ed.), Viruses and the gut. Proceedings of the 9th BSG-SK\&F International Workshop 1988. Smith Kline \& French Laboratories Limited, Welwyn Garden City, England.

8. Gouvea, V., R. I. Glass, P. Woods, K. Taniguchi, H. F. Clark, B. Forrester, and Z. Y. Fang. 1990. Polymerase chain reaction amplification and typing of rotavirus nucleic acid from stool specimens. J. Clin. Microbiol. 28:276-282.

9. Greenberg, H. B., M. Skaar, and S. S. Monroe. 1990. The 22 to $33 \mathrm{~nm}$ gastroenteritis agents of man, p. 137-159. In L. J. Saif and K. W. Theil (ed.), Viral diarrheas of man and animals. CRC Press, Inc., Boca Raton, Fla.

10. Greenberg, H. B., J. R. Valdesuso, A. R. Kalica, R. G. Wyatt, V. J. McAuliffe, A. Z. Kapikian, and R. M. Chanock. 1981. Proteins of Norwalk virus. J. Virol. 37:994-999.

11. Greenberg, H. B., R. G. Wyatt, J. Valdesuso, A. R. Kalica, W. T. London, R. M. Chanock, and A. Z. Kapikian. 1978. Solid-phase microtiter radioimmunoassay for detection of the Norwalk strain of acute nonbacterial, epidemic gastroenteritis virus and its antibodies. J. Med. Virol. 2:97-108.

12. Jansen, R. W., G. Siegl, and S. M. Lemon. 1990. Molecular epidemiology of human hepatitis A virus defined by an antigencapture polymerase chain reaction method. Proc. Natl. Acad. Sci. USA 87:2867-2871.

13. Jiang, X., D. Y. Graham, K. Wank, and M. K. Estes. 1990. Norwalk virus genome cloning and characterization. Science 250:1580-1583.

14. Kapikian, A. Z., and R. M. Chanock. 1990. Norwalk group of viruses, p. 671-693. In B. N. Fields and D. N. Knipe (ed.), Virology, 2nd ed. Raven Press, New York.

15. Kaplan, J. E., G. W. Gary, R. C. Baron, N. Singh, L. B. Schonberger, R. Feldman, and H. B. Greenberg. 1982. Epidemiology of Norwalk gastroenteritis and the role of Norwalk virus in outbreaks of acute nonbacterial gastroenteritis. Ann. Intern. Med. 96:756-761.

16. Maniatis, T., E. F. Fritsch, and J. Sambrook. 1982. Molecular cloning: a laboratory manual. Cold Spring Harbor Laboratory, Cold Spring Harbor, N.Y.

17. Matsui, S. M., J. P. Kim, H. B. Greenberg, W. Su, Q. Sun, P. C. Johnson, H. L. DuPont, L. Oshiro, and G. R. Reyes. 1991. The isolation and characterization of a Norwalk virus-specific cDNA. J. Clin. Invest. 87:1456-1461.

18. Palmenberg, A. 1987. Picornaviral protein alignments. Personal communication.

19. Persing, D. H. 1991. Polymerase chain reaction: trenches to benches. J. Clin. Microbiol. 29:1281-1285.

20. Robertson, B. H., B. Khanna, O. V. Nainan, and H. S. Margolis. 1991. Epidemiologic patterns of wild-type hepatitis A virus determined by genetic variation. J. Infect. Dis. 163:286-292.

21. Rotbart, H. A. 1990. Enzymatic amplification of the enteroviruses. J. Clin. Microbiol. 28:438-442.

22. Rychlik, W., and R. E. Rhoads. 1989. A computer program for choosing optimal oligonucleotides for filter hybridization, sequencing and in vitro amplification of DNA. Nucleic Acids Res. 17:8543-8551.

23. Wilde, J., J. Eiden, and R. Yolken. 1990. Removal of inhibitory substances from human fecal specimens for detection of group A rotaviruses by reverse transcriptase and polymerase chain reaction. J. Clin. Microbiol. 28:1200-1207. 